\title{
Substantive Innovation or Strategic Innovation? Research on Multiplayer Stochastic Evolutionary Game Model and Simulation
}

\author{
Junqiang Li, ${ }^{1}$ Hao Ren, ${ }^{1}$ Changcheng Zhang $\mathbb{D},{ }^{1,2}$ Qingxia Li $\mathbb{D},{ }^{3}$ and Kaifeng Duan ${ }^{1}$ \\ ${ }^{1}$ School of Economics and Management, Tongji University, Tongji Building A, Siping Road 1500, Yangpu District, \\ Shanghai 200092, China \\ ${ }^{2}$ Business School, Jinggangshan University, Ji'an 343009, China \\ ${ }^{3}$ Dongwu Business School, Soochow University, Suzhou 215006, China \\ Correspondence should be addressed to Changcheng Zhang; 1410371@tongji.edu.cn and Qingxia Li; lqx_myhk@163.com
}

Received 7 January 2020; Accepted 6 March 2020; Published 24 April 2020

Academic Editor: Oveis Abedinia

Copyright (c) 2020 Junqiang Li et al. This is an open access article distributed under the Creative Commons Attribution License, which permits unrestricted use, distribution, and reproduction in any medium, provided the original work is properly cited.

\begin{abstract}
Innovation subsidy is of great significance to promoting enterprise innovation development. However, in recent years, the frequent occurrence of R\&D subsidy deception in China has greatly reduced effectiveness of innovation. From the perspective of the strategic choice motivation of the innovation subject (including the enterprises, research institutions, and local governments), this paper constructs a multiplayer stochastic evolutionary game model. The influence of each variable on the subject strategy adoption is analyzed by simulation. There are two important findings in this paper. First, the paper confirms that there is an optimal boundary for the high subsidies received by enterprises and academic institutions, and the "subsidy boundary" is solved through the model. Second, this paper analyzes the effectiveness of the regulation of each variable through simulation and provides management and policy implications.
\end{abstract}

\section{Introduction}

In the past 40 years of reform and opening up, China's economic development has made great achievements. A number of major technical equipment related to national defense and people's livelihood have made outstanding achievements, such as manned space flight technology, Beidou satellite navigation, high-speed rail equipment, and supercomputer. However, compared with many developed countries that have completed industrialization, there is still a big gap in the comprehensive competitiveness of China in many industrial fields including integrated circuits, operating systems, and so on. In particular, the "ZTE incident (ZTE incident: the ZTE incident refers to the announcement of the US Department of Commerce in April 2018, claiming that the Chinese company ZTE will be banned from purchasing sensitive products from US companies in the next seven years; the core components of ZTE are facing the risk of default, and the company has experienced a major crisis; ZTE was lifted through a series of events, including multiparty negotiations, payment of huge fines, and deposits)," which broke out in April 2018, has triggered a profound reflection on the lack of industrial core technology. It can be said that if China wants to achieve high-quality economic development, innovation driving is imperative.

For a long time in the past, it is the competitive advantage of China to concentrate the main efforts to overcome certain technical problems or industrial difficulty. However, the construction of an innovative country should not be "sports-style" innovation ("sports-style" innovation, that is, through short-term government directives, policy incentives, and other means to stimulate innovation, has the characteristics of temporary, assault, etc., rather than an innovative way of lasting stability), but it should promote the technological innovation of China in an orderly way through the establishment of a rational and effective multiplayer cooperative innovation model including government, enterprises, and research institutions (including universities and scientific institutions). Technological innovation has two typical characteristics: huge cost input in the early stage 
and uncertainty of market income, which will lead to the lack of innovation enthusiasm of the innovation subject. In order to promote technological innovation, governments around the world generally use public R\&D subsidies to encourage enterprises to increase their investment in innovative research and development (R\&D) [1,2]. The Chinese government has been heavily subsidizing innovation in industry-university-research cooperation. However, in the past few years, there have been numerous cases of science and technology deception. The motivation behind a series of innovative deception for subsidies is worth pondering.

At present, a large number of literatures have conducted research on enterprise innovation content and innovation way. However, there are very few literatures analyzing the innovation behavior of enterprises from the perspective of innovation strategy choice motivation. In fact, in addition to "substantive innovation" behavior aimed at promoting technological progress and maintaining competitive advantage, there are also innovative activities aimed at obtaining other benefits, which are a typical "strategic" behavior. The one-sided pursuit of innovation "quantity" to meet government policies so as to get government subsidies is a typical behavior of "strategic innovation." Currently, the innovation environment of enterprises is highly uncertain, which can be easily affected by emotional infection of innovation subjects and the interference of the external environment. Under the circumstances, "strategic innovation" behavior is especially easy to occur. Against this backdrop, this paper attempts to construct a multiplayer stochastic evolutionary game model under uncertainty environment from the perspective of tripartite cooperation of the enterprises, research institutions, and local governments and then solve the stability conditions of the three parties jointly promoting the substantial innovation behavior and explore the deep motivation of enterprises and research institutions choosing "substantive innovation" and "strategic innovation" behaviors. Besides, the paper also gives a simulation analysis of the related core variables in a random environment and analyzes the influence of each variable on direction and degree of the subject strategic choice from the perspective of quantitative analysis. It is an effective attempt for the academic circles to simulate and analyze the tripartite stochastic evolutionary game.

In general, the contributions of this paper are as follows. (1) Methodologically: this paper introduces the stochastic system into the multiplayer evolutionary game model, which provides a new perspective to study the strategy adoption in stochastic environment. (2) In terms of simulation, this paper obtains the data through questionnaire. The data verify the correctness of the stability condition of the equilibrium solution. Moreover, through simulation design, this paper analyzes the influence of each variable on direction and degree of the subject strategy selection originality and provides a new perspective for the tripartite stochastic evolution game simulation. (3) Theoretically and practically, through the model solving and simulation, this paper finds that the high subsidies given by local governments to enterprises and academic institutions are not as high as possible, and the "subsidy boundary" is solved through the model. In addition, through simulation, this paper also finds that the influence of relevant variables on subject strategic choice differs in direction and degree. From the perspective of regulatory efficiency, it also analyzes the degree of the effectiveness of the regulation of different variables, which have certain theoretical contributions and practical implications.

\section{Literature Review}

2.1. Multiplayer Collaborative Innovation. Resource complementarity is an important reason for choosing collaborative innovation among subjects. Gassmann et al. believed that with the increasing technological complexity and market competition, cooperative innovation would become an inevitable choice for enterprises to break through their resource limitations [3]. Aggarwal et al. also believed that resource complementarity promotes cooperative innovation and the degree of resource dependence would affect knowledge sharing and innovation performance among organizations [4]. Through empirical research, Heil and Bornemann demonstrated that the integration of $\mathrm{R} \& \mathrm{D}$ resources would affect the investor's evaluation on future cooperative performance [5].

Focusing on multiplayer cooperative innovation, scholars have carried out a lot of research from the perspectives of industry-university-research, interenterprise, interorganization, and interemployee. It is widely acknowledged that multiplayer cooperative innovation can improve the performance of intersubject collaborative innovation [6-10]. In order to have a better evaluation of the performance of multiplayer collaborative innovation, Albats et al. refined the key performance indicators of each subject in industry-university-research cooperative innovation [11]. Furthermore, scholars have also carried out in-depth research studies on the effects of collaborative innovation performance. Schulze and Brojerdi studied the relationship between knowledge distance and collaborative innovation performance [12]. Zhao et al. took the external control mechanism (resource input mechanism) and the internal interaction mechanism (interaction mechanism) as the research breakthrough point and revealed the principles of collaborative innovation of knowledge-intensive competition alliance [13]. Tsai focused on the absorptive capacity and studied the relationship between competitor cooperation and new product innovation performance in different situations [6]. Yang et al. studied the influence of enterprise collaborative culture and knowledge sharing on enterprise innovation (including product innovation and process innovation) [14].

In recent years, the collaborative innovation network has also aroused great interest in academia. De Noni et al. started with the regional level of development differentiation and verified the impact of collaborative networks on innovation performance by studying cooperative networks among local organizations [15]. Taking nanoenergy industry as an example, Guan and Liu analyzed the influence of knowledge networks and collaborative networks on exploitative innovation and exploratory innovation [16]. Najafi-Tavani et al. 
regarded innovation capabilities of product and process as two mechanisms and studied how the two mechanisms affect the performance of new products through collaborative innovation networks [17]. Xie et al. studied the relationship between collaborative network and knowledge transfer performance [18]. Crescenzi et al. believed that the industryuniversity-research cooperation is crucial and pointed out that openness and richness of collaborative network were important factors of collaborative innovation [19].

2.2. Innovation Subsidy. The past two decades have witnessed the ongoing debate over the effectiveness of $R \& D$ subsidy. Cerulli and Potì indicated that large enterprises were more capable to bear risks than small enterprises. Government subsidies would promote large enterprises to increasing $\mathrm{R} \& \mathrm{D}$ investment but would crowd out small enterprises' R\&D investment [20]. Wang et al. pointed out that both green insurance subsidies and government subsidies could promote enterprise innovation, but green insurance subsidies had lower innovation risks than direct subsidies [21]. Greco et al. showed that public subsidies could promote the achievement of the goal of open innovation [22]. Chang et al. used game theory to study the joint tax subsidy mechanism of government, manufacturers, and recyclers and believed that joint tax subsidy mechanism could encourage manufacturers to conduct ecological innovation [23]. Tsai and Liao pointed out that market demand and government subsidies had a positive moderating effect on the relationship between environmental strategy and ecological innovation [24]. Huang et al. revealed the relationship between the scale of government subsidies and the innovation efficiency of enterprises and implied that there was a "U-shaped" relationship between them [25]. Chapman et al. indicated that $\mathrm{R} \& \mathrm{D}$ subsidies had a positive impact on the breadth of external cooperation of enterprises [26]. Catozzella and Vivarelli argued that government subsidies would have a negative impact on the innovation productivity of enterprises and government intervention would increase enterprises' innovation expenditure [27]. Wu proposed that receiving $R \& D$ subsidies would increase the probability of enterprise external financing. Compared with state-owned enterprises, government subsidies had a stronger signal effect on private enterprises [28]. Wei and Zuo studied the difference of R\&D subsidies' influence between local governments and central government on enterprise's access to external capital [29]. Morimoto believed that although $R \& D$ subsidies could increase entrepreneurs' $R \& D$ activities, there is an inverted U-shaped relationship between R\&D subsidies and R\&D growth [30].

Other scholars focused on the factors of R\&D subsidy and studied the effects of R\&D subsidies in specific situations. Sun et al. conducted a comparative study on consumer subsidies and manufacturer subsidies in electric vehicle industry [31]. They held that consumer subsidies can promote popularization and technological breakthrough of electric vehicles more greatly than manufacturer subsidies. Chen et al. studied the relationship between $R \& D$ subsidies and IPO performance and discussed the influence of state ownership and patent intensity on the relationship between them [32]. Dai and Shen argued that there was a complementary relationship between optimal IPR protection and government subsidies [33].

Some scholars also paid attention to the relationship between R\&D subsidy and enterprise innovation behaviors. Boeing pointed out that government R\&D subsidy would crowd out enterprise $R \& D$ investment [34]. Bronzini and Piselli found that innovation subsidy could significantly improve the probability of patent application of small enterprises [35]. Cheng et al. carried out research from the perspective of political connection and believed that political connection helps enterprises to obtain tax incentives and government subsidies [36]. Basit et al. studied innovation subsidy in service industry and found that enterprises can significantly improve their performance through marketing innovation [37]. Some scholars also paid attention to the problem of corporate fraud for subsidy. For instance, Zuo et al. put forward a new decision-making model to help decision makers choose appropriate R\&D subsidy objects [38].

2.3. Evolutionary Game. There are abundant research studies on evolutionary game, which mainly shows three trends as follows:

First, the theoretical research method of evolutionary game has been constantly optimized, which has more explanatory power to the real situation. Deng et al. developed the Jaccard matrix game to suppress counterintuitive behaviors in evidence theory from the perspective of evolutionary game [39]. Xu et al. proposed an information flow game based on evolutionary game in order to study how information spreads in the market [40]. Jensen and Rigos studied evolutionary game with nonuniform random matching by using pure strategies [41]. Liu et al. used evolutionary game and multiagent simulation to analyze the cooperative and non-cooperative behaviors of agricultural irrigators and industrial water users [42]. Wu et al. introduced a "righteous agent" in the evolutionary game to study the evolution of cooperation [43]. In addition, the gamification framework is becoming popular. Gamification is the use of elements traditionally associated with games, such as structured rules, points, and competition, aiming at prompting desired behaviors in individuals $[44,45]$. These studies are instructive for game theory research, especially for the part of games' hypotheses.

Second, game subjects and strategies are increasingly enriched, and various game scenarios are discussed. Xie et al. studied relevant strategies for farmland protection by constructing two three-party evolutionary game models between central government, local governments, and farmers [46]. Shi et al. built an evolutionary game model of multiple suppliers' behaviors based on the cooperation among suppliers [47]. Yang et al. analyzed the behaviors of Government-Industry- 
University-Research cooperation from two aspects of market mechanism and supervision mechanism [48]. Antoci and Sabatini constructed an evolutionary game model in which agents can choose among three strategies of social participation [49]. Encarnação et al. developed a theoretical model based on strategic interaction among different industry participants (governments, companies, and consumers) by virtue of the evolutionary game theory [50].

Third, evolutionary game theory has been extended to more research fields. Shu et al. proposed an evolutionary game model with three structures of supply chain leadership [51]. Cui et al. considered that the essential mechanism to restrict the development of green agriculture was the inefficiency of technology diffusion between supply and demand sides of green technology and developed the evolutionary game models between the government and farmers [52]. Liu et al. used evolutionary game theory to study the long-term dynamic process of multiplayer game in coal mine safety supervision [53]. Wang developed an evolutionary game model between local governments and developer group around the scale development of green buildings [54]. Chen and $\mathrm{Hu}$ developed an evolutionary game theory model of the interaction between governments and manufacturers based on static carbon taxes and subsidies and analyzed the evolutionary behaviors of the governments and manufacturers under three additional models [55].

2.4. Summary. In general, scholars have conducted a lot of beneficial research studies on collaborative innovation, innovation subsidy, and evolutionary game, but there are still some gaps which need to be addressed in future study. Firstly, current studies mainly focused on the mode and effect of industry-university-research cooperation, but motivation analysis of strategy adoption in industry-university-research cooperation innovation was inadequate. Secondly, research related to R\&D subsidy still focused on the level of subsidy rationality and impact on heterogeneous enterprises, which fail to quantitatively analyze the effective boundary of innovation subsidy. Thirdly, a large number of scholars used the evolutionary game theory to study collaborative innovation but neglected the influence of stochastic dynamic environment and high uncertainty on strategy adoption. In particular, there is a lack of simulation method to analyze the shifting trends of variables in uncertain environment. In this context, we attempt to construct a multiplayer stochastic evolutionary game model of Government-Industry-University-Research on collaborative innovation and analyze the effective boundary of innovation subsidy. We analyze the influence of different variables on the strategy adoption under stochastic interference environment so as to promote substantive innovation of industry-university-research with innovation subsidy.
2.5. Framework. We provide a framework to clarify our research (Figure 1). First, based on the classical evolutionary game model, we consider the stochastic interference influence on strategy adoption and construct a stochastic evolutionary game model. Second, we find the stable condition of cooperation strategy adoption, that is, the existence of the "boundary" of subsidy received by enterprises and institutions, while both players will adopt the cooperation strategy. Third, we collect data for simulation to compare the effects of variables. Fourth, we discuss the results and put forward some suggestions.

\section{Establishment and Analysis of Evolutionary Game Model}

\subsection{Basic Hypothesis}

3.1.1. Hypothesis 1. The game subject is mainly composed of the enterprises, research institutions, and local governments. Strategy that can be taken by the enterprises and research institutions is "strategic innovation" or "substantial innovation." The probability of strategy selection of the enterprises is $x$ and $1-x$, respectively, while the probability of strategic selection of the research institutions is $y$ and $1-y$, respectively. The action taken by the local governments is "giving low subsidy" or "giving high subsidy," and the probability of action selection of it is $z$ and $1-z$, respectively.

3.1.2. Hypothesis 2. The local government tends to give subsidies for innovation in support of the industry-university-research cooperation. Generally, in order to promote cooperation between enterprises and research institutions, innovation subsidies are often distributed in the form of a joint declaration project. Therefore, it is assumed that both players can receive government subsidies only by joint declaration. When the governments have high enthusiasm for supporting innovation and strong financial strength, they tend to give high subsidies to the enterprises and research institutions (marked as $H_{1}$ and $H_{2}$, respectively), while on the contrary, they give low subsidies (marked as $L_{1}$ and $L_{2}$, respectively).

3.1.3. Hypothesis 3. In general, only cooperation among enterprises familiar with industrial development and market demand, research institutions with strong scientific research strength, and local governments that provide financial support for innovation can successfully promote the development of industrial innovation. Therefore, we assume that industrial innovation can only be successful when the local governments provide high subsidies, and only when the enterprises and research institutions cooperate and adopt substantial innovation strategy can industrial innovation be successful. At this point, the income of the enterprises and research institutions are $S_{1}$ and $S_{2}$, respectively, and the cost input of both sides is $C_{1}$ and $C_{2}$. After the success of industrial innovation, the local governments gain comprehensive income $G_{1}$ due to the increase of industrial value and the improvement of political performance. When both the 


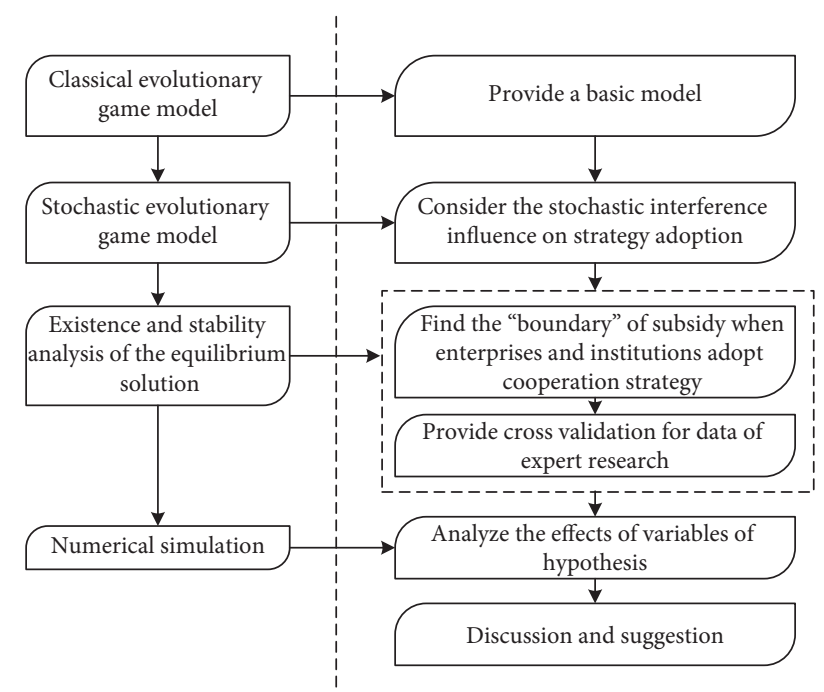

FIgURE 1: The framework of research.

enterprises and research institutions adopt substantial innovation strategy and the local governments give low subsidies (or without subsidies), innovation enthusiasm damage on both sides can be symbolized as $K_{1}$ and $K_{2}$; the income obtained by local governments at this time is $G_{2}$.

3.1.4. Hypothesis 4. When both the enterprises and research institutions adopt strategic innovation, "grey interest alliance" (the game subjects obtain benefit illegally through alliance) would be built for applying for government innovation subsidies. Once the alliance is built, both sides would not invest the innovation cost in order to obtain higher returns. At this time, the benefits of both sides are $H_{1}$ and $\mathrm{H}_{2}$, respectively. In order to obtain high subsidies, they may deliver grey benefits to relevant sectors or individuals, thereby causing costs $B_{1}$ and $B_{2}$. For their profit purpose, it is considered that $B_{i}<C_{i}(i=1,2)$. For the local governments, although the formation of the "grey interest alliance" between enterprises and research institutions cannot really promote industrial progress or bring significant economic benefits, it may bring some social benefits (marked as $G_{3}$ ) due to the establishment of major cooperation projects and some innovation output required by the projects (e.g., patents, papers, and awards). When the local governments give low subsidy, the enthusiasm of the innovation subjects is insufficient and the local governments are assumed to be unable to obtain the relevant benefits. Only when the local governments give high subsidies, it can be assumed that the local governments would take regulatory measures, where the regulatory cost is set as $M$ here. Once the enterprises and research institutions have built a "grey interest alliance," it will be of strong concealment. For the local governments, the governance can be more difficult with higher supervision costs. Certainly, the "grey interest alliance" could be exposed by society and punished by the government with a certain probability $\delta$. At this time, it is assumed that the damage to the reputation of the local governments is $T$, and the penalties paid by the enterprises and research institutions are $F_{1}$ and $F_{2}$, respectively.
3.1.5. Hypothesis 5. For enterprises and research institutions, if one side chooses strategic innovation and the other chooses substantive innovation, the two sides will build "grey interest alliance" to apply for high subsidies from local governments. The local governments will obtain benefits $G_{4}$, and the subject adopting the substantive innovation strategy will invest a certain cost $C_{3}$. If the local governments give low subsidies, then both sides directly receive low subsidies.

3.2. Payoff Matrix Analysis. When both the enterprises and research institutions adopt substantive innovation strategy and the local governments choose to give high subsidies, the income of the enterprises is $S_{1}-C_{1}$, the income of the research institutions is $S_{2}-C_{2}$, and the income of the local governments is $G_{1}-H_{1}-H_{2}-M$. When the enterprises adopt substantive innovation strategy but the research institutions adopt strategic innovation strategy and the local governments choose to give high subsidies, the income of the enterprises is $H_{1}-C_{3}-B_{1}-\delta F_{1}$, the income of the research institutions is $H_{2}-B_{2}-\delta F_{2}$, and the income of the local governments is $G_{4}-H_{1}-H_{2}-M-\delta T$. When the research institutions adopt the substantive innovation strategy but the enterprises adopt the strategic innovation strategy and the local governments choose to give high subsidies, then the income of the enterprises is $H_{1}-B_{1}-\delta F_{1}$, the income of the research institutions is $H_{2}-C_{3}-B_{2}-\delta F_{2}$, and the income of the local governments is $G_{4}-H_{1}-H_{2}-M-\delta T$. When both the enterprises and research institutions adopt the strategic innovation strategies and the local governments choose to give low subsidies, then the income of the enterprises is $L_{1}$ and the income of the research institutions is $L_{2}$. At this time, the income of the local governments is $-L_{1}-L_{2}$. When both the enterprises and the research institutions adopt the substantive innovation strategies and the local governments choose to give low subsidies, then the income of the enterprises is $L_{1}-C_{1}-K_{1}$, the income of the research institutions is $L_{2}-C_{2}-K_{2}$, and the income of the local governments is $G_{2}-L_{1}-L_{2}$. When the enterprises adopt substantive innovation strategy but the research institutions adopt strategic innovation strategy and the local governments choose to give low subsidies, the income of the enterprises is $L_{1}-C_{3}$, the income of the research institutions is $L_{2}$, and the income of the local governments is $G_{4}-L_{1}-L_{2}$. It is worth noting that when at least one party adopts strategic innovation strategy, the innovation subjects will have the motivation to deliver grey benefits. However, the occurrence of the costs $B_{1}$ and $B_{2}$ depends on whether the local governments give high subsidies. If the local governments give high subsidies, the grey benefits will be received by relevant sectors or individuals, and the cost $\left(B_{1}\right.$ and $B_{2}$ ) of the enterprises and the research institutions will be generated. Conversely, if the local governments give low subsidy, the costs $B_{1}$ and $B_{2}$ will not be generated. When the research institutions adopt substantive innovation strategy but the enterprises adopt the strategic innovation strategy and the local governments choose to give low subsidies, the income of the enterprises is $L_{1}$, the income of the research institutions is $L_{2}-C_{3}$, and the income of the local 
governments is $G_{4}-L_{1}-L_{2}$. When both the enterprises and the research institutions adopt strategic innovation strategies and the local governments choose to give high subsidies, then the income of the enterprises is $H_{1}-B_{1}-\delta F_{1}$, the income of the research institutions is $\mathrm{H}_{2}-\mathrm{B}_{2}-\delta F_{2}$, and the income of the local governments is $G_{3}-H_{1}-H_{2}-M-\delta T$.

The specific payoff matrix is shown in Table 1 .
3.3. Replicator Dynamics Equation. Setup $U_{11}$ represents the expected income of the enterprises under the choice of strategic innovation strategy, $U_{12}$ represents the expected income of the enterprises' choice of substantive innovation strategy, and $\bar{U}_{1}$ represents the average expected income of the enterprises. Then,

$$
\begin{aligned}
U_{11}= & (1-\mathrm{y})(1-\mathrm{z})\left(H_{1}-B_{1}-\delta F_{1}\right)+(1-y) z L_{1}+y(1-z)\left(H_{1}-B_{1}-\delta F_{1}\right)+y z L_{1}, \\
U_{12}= & (1-y)(1-z)\left(S_{1}-C_{1}\right)+(1-y) z\left(L_{1}-C_{1}-K_{1}\right)+y(1-z)\left(H_{1}-C_{3}-B_{1}-\delta F_{1}\right)+y z\left(L_{1}-C_{3}\right), \\
\bar{U}_{1}= & x U_{11}+(1-x) U_{12}=x(1-\mathrm{y})(1-\mathrm{z})\left(H_{1}-B_{1}-\delta F_{1}\right)+x(1-y) z L_{1}+x y(1-z)\left(H_{1}-B_{1}-\delta F_{1}\right)+x y z L_{1} \\
& +(1-x)(1-y)(1-z)\left(S_{1}-C_{1}\right)+(1-x)(1-y) z\left(L_{1}-C_{1}-K_{1}\right)+(1-x) y(1-z)\left(H_{1}-C_{3}-B_{1}-\delta F_{1}\right) \\
& \quad+(1-x) y z\left(L_{1}-C_{3}\right) .
\end{aligned}
$$

Setup $U_{21}$ represents the expected income of the research institutions under the choice of strategic innovation strategy, $U_{22}$ represents the expected income of the research institutions under the choice of substantive innovation strategy, and $\bar{U}_{2}$ represents the average expected income of the research institutions. Then,

$$
\begin{aligned}
U_{21}= & (1-x)(1-z)\left(H_{2}-B_{2}-\delta F_{2}\right)+(1-x) z L_{2}+x(1-z)\left(H_{2}-B_{2}-\delta F_{2}\right)+x z L_{2}, \\
U_{22}= & (1-x)(1-z)\left(S_{2}-C_{2}\right)+(1-x) z\left(L_{2}-C_{2}-K_{2}\right)+x(1-z)\left(H_{2}-C_{3}-B_{2}-\delta F_{2}\right)+x z\left(L_{2}-C_{3}\right), \\
\bar{U}_{2}= & y U_{21}+(1-y) U_{22}=(1-x) y(1-z)\left(H_{2}-B_{2}-\delta F_{2}\right)+(1-x) y z L_{2}+x y(1-z)\left(H_{2}-B_{2}-\delta F_{2}\right)+x y z L_{2} \\
& +(1-x)(1-y)(1-z)\left(S_{2}-C_{2}\right)+(1-x)(1-y) z\left(L_{2}-C_{2}-K_{2}\right)+x(1-y)(1-z)\left(H_{2}-C_{3}-B_{2}-\delta F_{2}\right) \\
& \quad+x(1-y) z\left(L_{2}-C_{3}\right)
\end{aligned}
$$

Setup $U_{31}$ represents the expected income when the local governments choose to give low subsidies, $U_{32}$ represents the expected income when the local governments choose to give high subsidies, and $\bar{U}_{3}$ represents the average expected income of the local governments. Then,

$$
\begin{aligned}
U_{31}= & (1-x)(1-y)\left(G_{2}-L_{1}-L_{2}\right)+(1-x) y\left(G_{4}-L_{1}-L_{2}\right)+x(1-y)\left(G_{4}-L_{1}-L_{2}\right)+x y\left(-L_{1}-L_{2}\right), \\
U_{32}= & (1-x)(1-y)\left(G_{1}-H_{1}-H_{2}-M\right)+(1-x) y\left(G_{4}-H_{1}-H_{2}-M-\delta T\right)+x(1-y)\left(G_{4}-H_{1}-H_{2}-M-\delta T\right) \\
& +x y\left(G_{3}-H_{1}-H_{2}-M-\delta T\right), \\
\bar{U}_{3}= & z U_{31}+(1-z) U_{32}=(1-x)(1-y) z\left(G_{2}-L_{1}-L_{2}\right)+(1-x) y z\left(G_{4}-L_{1}-L_{2}\right)+x(1-y) z\left(G_{4}-L_{1}-L_{2}\right) \\
& +x y z\left(-L_{1}-L_{2}\right)+(1-x)(1-y)(1-z)\left(G_{1}-H_{1}-H_{2}-M\right)+(1-x) y(1-z)\left(G_{4}-H_{1}-H_{2}-M-\delta T\right) \\
& \quad+x(1-y)(1-z)\left(G_{4}-H_{1}-H_{2}-M-\delta T\right)+x y(1-z)\left(G_{3}-H_{1}-H_{2}-M-\delta T\right) .
\end{aligned}
$$


TABle 1: Payoff matrix of enterprises, research institutions, and local governments.

\begin{tabular}{lccr}
\hline Strategic combination & Enterprises & Research institutions & Local governments \\
\hline (Substantive, substantive, high subsidy) & $S_{1}-C_{1}$ & $S_{2}-C_{2}$ & $G_{1}-H_{1}-H_{2}-M$ \\
(Substantive, substantive, low subsidy) & $L_{1}-C_{1}-K_{1}$ & $G_{2}-L_{1}-L_{2}$ \\
(Substantive, strategic, high subsidy) & $H_{1}-C_{3}-B_{1}-\delta F_{1}$ & $H_{2}-B_{2}-\delta F_{2}$ & $G_{4}-H_{1}-H_{2}-M-\delta T$ \\
(Substantive, strategic, low subsidy) & $L_{1}-C_{3}$ & $L_{2}$ & $G_{4}-L_{1}-L_{2}$ \\
(Strategic, substantive, high subsidy) & $H_{1}-B_{1}-\delta F_{1}$ & $H_{2}-C_{3}-B_{2}-\delta F_{2}$ & $G_{4}-H_{1}-H_{2}-M-\delta T$ \\
(Strategic, substantive, low subsidy) & $L_{1}$ & $L_{2}-C_{3}$ & $G_{4}-L_{1}-L_{2}$ \\
(Strategic, strategic, high subsidy) & $H_{1}-B_{1}-\delta F_{1}$ & $H_{2}-B_{2}-\delta F_{2}$ & $G_{3}-H_{1}-H_{2}-M-\delta T$ \\
(Strategic, strategic, low subsidy) & $L_{1}$ & $L_{2}$ & $-L_{1}-L_{2}$ \\
\hline
\end{tabular}

Replication dynamic equations of the enterprises, the research institutions, and the local governments are $F_{1}(x)$, $F_{2}(y)$, and $F_{3}(z)$.

$$
\begin{aligned}
& F_{1}(x)=\frac{\mathrm{d} x}{\mathrm{~d} t}=x\left(U_{11}-\bar{U}_{1}\right)=x(1-x)\left(U_{11}-U_{12}\right), \\
& F_{2}(y)=\frac{\mathrm{d} y}{\mathrm{~d} t}=y\left(U_{21}-\bar{U}_{2}\right)=y(1-y)\left(U_{21}-U_{22}\right), \\
& F_{3}(z)=\frac{\mathrm{d} z}{\mathrm{~d} t}=z\left(U_{21}-\bar{U}_{2}\right)=z(1-z)\left(U_{31}-U_{32}\right) .
\end{aligned}
$$

Since $x, y, z \in[0,1], 1-x, 1-y$, and $1-z$ are all nonnegative, which will not affect the results of strategy evolution. Therefore, the replication dynamic equations of the three players are modified as follows:

$$
\begin{aligned}
F_{1}(x)= & \frac{\mathrm{d} x}{\mathrm{~d} t}=x\left(U_{11}-U_{12}\right)=x\left[(-1+y+z-y z) B_{1}-(-1+y) c_{1}+y c_{3}-\delta F_{1}+y \delta F_{1}+z \delta F_{1}-y z \delta F_{1}\right. \\
& \left.+H_{1}-y H_{1}-z H_{1}+y z H_{1}+z k_{1}-y z k_{1}-S_{1}+y S_{1}+z S_{1}-y z S_{1}\right] \\
F_{2}(y)= & \frac{\mathrm{d} y}{\mathrm{~d} t}=y\left(U_{21}-U_{22}\right)=y\left[(-1+x+z-x z) B_{2}-(-1+x) c_{2}+x c_{3}-\delta F_{2}+x \delta F_{2}+z \delta F_{2}-x z \delta F_{2}\right. \\
& \left.+H_{2}-x H_{2}-z H_{2}+x z H_{2}+z k_{2}-x z k_{2}-S_{2}+x S_{2}+z S_{2}-x z S_{2}\right], \\
F_{3}(z)= & \frac{\mathrm{d} z}{\mathrm{~d} t}=z\left(U_{31}-U_{32}\right)=z\left[M+T x \delta+T y \delta-T x y \delta+(-1+x+y-x y) G_{1}+(-1+x)(-1+y) G_{2}-x y G_{3}\right. \\
& \left.+H_{1}+H_{2}-L_{1}-L_{2}\right] .
\end{aligned}
$$

\section{Stochastic Evolutionary Game Model}

4.1. Turbulence Factors of Stochastic System. In reality, in the process of industrial technology innovation, strategy adoption of the enterprises, research institutions, and local governments will be affected by turbulence factors. At the external level, it is mainly affected by the complexity of social interests; at the internal level, it is mainly affected by emotional changes of the participants, moral hazard, and so on.

Therefore, in order to make the multiplayer game process more consistent with the reality, Gaussian white noise is introduced into the replication dynamic equations [56]:

$$
\begin{aligned}
\mathrm{d} x(t)= & {\left[(-1+y+z-y z) B_{1}-(-1+y) c_{1}+y c_{3}-\delta F_{1}+y \delta F_{1}+z \delta F_{1}-y z \delta F_{1}+H_{1}-y H_{1}-z H_{1}+y z H_{1}\right.} \\
& \left.+z k_{1}-y z k_{1}-S_{1}+y S_{1}+z S_{1}-y z S_{1}\right] x(t) \mathrm{d} t+\sigma x(t) \mathrm{d} \omega(t), \\
\mathrm{d} y(t)= & {\left[(-1+x+z-x z) B_{2}-(-1+x) c_{2}+x c_{3}-\delta F_{2}+x \delta F_{2}+z \delta F_{2}-x z \delta F_{2}+H_{2}-x H_{2}-z H_{2}+x z H_{2}\right.} \\
& \left.+z k_{2}-x z k_{2}-S_{2}+x S_{2}+z S_{2}-x z S_{2}\right] y(t) \mathrm{d} t+\sigma y(t) \mathrm{d} \omega(t),
\end{aligned}
$$




$$
\begin{aligned}
\mathrm{d} z(t)= & {\left[M+T x \delta+T y \delta-T x y \delta+(-1+x+y-x y) G_{1}+(-1+x)(-1+y) G_{2}-x y G_{3}+H_{1}\right.} \\
& \left.+H_{2}-L_{1}-L_{2}\right] z(t) \mathrm{d} t+\sigma z(t) \mathrm{d} \omega(t) .
\end{aligned}
$$

In the equations, $\omega(t)$ is a one-dimensional standard Brown motion. The Brown motion is an irregular stochastic fluctuation phenomenon, which can well reflect how players are affected by stochastic factors. $\mathrm{d} \omega(t)$ denotes the Gaussian white noise. When $t>0$, time step $h>0$, and its increment $\Delta \omega(t)=\omega(t+h)-\omega(t)$ has a normal distribution $N(0, \sqrt{h})$. $\sigma$ represents the intensity of the random disturbance.
4.2. Existence and Stability of Trivial Solution. For equations (5)-(7), it is assumed that the initial time of the three-player game $t=0$; at this point, $x(0)=0, y(0)=0$, and $z(0)=0$; then,

$$
\begin{aligned}
& {\left[(-1+y+z-y z) B_{1}-(-1+y) c_{1}+y c_{3}-\delta F_{1}+y \delta F_{1}+z \delta F_{1}-y z \delta F_{1}+H_{1}-y H_{1}-z H_{1}+y z H_{1}+z k_{1}-y z k_{1}-S_{1}+y S_{1}\right.} \\
& \left.\quad+z S_{1}-y z S_{1}\right] 0+\sigma x(t) \mathrm{d} \omega(t)=0
\end{aligned}
$$

$$
\begin{aligned}
& {\left[(-1+x+z-x z) B_{2}-(-1+x) c_{2}+x c_{3}-\delta F_{2}+x \delta F_{2}+z \delta F_{2}-x z \delta F_{2}+H_{2}-x H_{2}-z H_{2}+x z H_{2}+z k_{2}-x z k_{2}-S_{2}+x S_{2}\right.} \\
& \left.\quad+z S_{2}-x z S_{2}\right] 0+\sigma y(t) \mathrm{d} \omega(t)=0
\end{aligned}
$$

$$
\left[M+T x \delta+T y \delta-T x y \delta+(-1+x+y-x y) G_{1}+(-1+x)(-1+y) G_{2}-x y G_{3}+H_{1}+H_{2}-L_{1}-L_{2}\right] \cdot 0+\sigma z(t) \mathrm{d} \omega(t)=0
$$

According to equations (11)-(13), it can be obtained that $\left.\mathrm{d} \omega(t)\right|_{t=0}=\omega /\left.(t) \mathrm{d} t\right|_{t=0}=0$, so there is at least zero solution to the equations. This indicates that the system will stay in this state all the time without interference of white noise, so the zero solution is the trivial solution of the equation.

However, in reality, the system is bound to be disturbed by the internal and external environment, which has an impact on the stability of the system. Therefore, the turbulence factors of the system stability must be considered. According to the stability discriminant theorem of stochastic differential equation, the stability of the three-player evolutionary game equation can be judged. The stability discriminant theorem is as follows [57].

A stochastic differential equation is given as

$$
\begin{aligned}
\mathrm{d} x(t) & =f(t, x(t)) \mathrm{d} t+g(t, x(t)) \mathrm{d} \omega(t), \\
x\left(t_{0}\right) & =x_{0} .
\end{aligned}
$$

Given a function $V(t, x)$ and positive constants $c_{1}, c_{2}$, there exists $c_{1}|x|^{p} \leq V(t, x) \leq c_{2}|x|^{p}, t \geq 0$.
(1) If there is a positive constant $\gamma$, which satisfies $L V(t, x) \leq-\gamma V(t, x), t \geq 0$, then the zero solution $p$ th moment of equation (14) is exponentially stable, and $E\left|x\left(t, x_{0}\right)\right|^{p}<\left(c_{2} / c_{1}\right)\left|x_{0}\right|^{p} e^{-\gamma t}, t \geq 0$.

(2) If there is a positive constant $\gamma$, which satisfies $L V(t, x) \geq-\gamma V(t, x), t \geq 0$, then the zero solution $p$ th moment exponential of equation (14) is stable, and $E\left|x\left(t, x_{0}\right)\right|^{p} \geq\left(c_{2} / c_{1}\right)\left|x_{0}\right|^{p} e^{-\gamma t}, t \geq 0$.

For equations (8)-(10), let $V_{t}(t, x)=x, V_{t}(t, y)=y$, $V_{t}(t, z)=z, x \in[0,1], \quad y \in[0,1], z \in[0,1], \quad c_{1}=c_{2}=1$, $p=1$, and $\gamma=1$; then, $L V(t, x)=f(t, x)=[(-1+y+z-$ $y z) B_{1}-(-1+y) c_{1}+y c_{3}-\delta F_{1}+y \delta F_{1}+z \delta F_{1}-y z \delta F_{1}+$ $H_{1}-y H_{1}-z H_{1}+y z H_{1}+z k_{1}-y z k_{1}-S_{1}+y S_{1}+z S_{1}-$ $\left.y z S_{1}\right] x, \quad L V(t, y)=f(t, y)=\left[(-1+x+z-x z) B_{2}-(-1+\right.$ x) $c_{2}+x c_{3}-\delta F_{2}+x \delta F_{2}+z \delta F_{2}-x z \delta F_{2}+H_{2}-x H_{2}-z$ $\left.H_{2}+x z H_{2}+z k_{2}-x z k_{2}-S_{2}+x S_{2}+z S_{2}-x z S_{2}\right] y$, and $L V$ $(t, z)=f(t, z)=[M+T x \delta+T y \delta-T x y \delta+(-1+x+y-$ $\left.x y) G_{1}+(-1+x)(-1+y) G_{2}-x y G_{3}+H_{1}+H_{2}-L_{1}-L_{2}\right] z$.

If the zero solution $p$-th moment exponential of equation (8)-(10) is stable, it needs to satisfy [58]

$$
\begin{aligned}
& {\left[(-1+y+z-y z) B_{1}-(-1+y) c_{1}+y c_{3}-\delta F_{1}+y \delta F_{1}+z \delta F_{1}-y z \delta F_{1}+H_{1}-y H_{1}-z H_{1}+y z H_{1}+z k_{1}-y z k_{1}-S_{1}+y S_{1}\right.} \\
& \left.\quad+z S_{1}-y z S_{1}\right] x \leq-x
\end{aligned}
$$

$$
\begin{aligned}
& {\left[(-1+x+z-x z) B_{2}-(-1+x) c_{2}+x c_{3}-\delta F_{2}+x \delta F_{2}+z \delta F_{2}-x z \delta F_{2}+H_{2}-x H_{2}-z H_{2}+x z H_{2}+z k_{2}-x z k_{2}-S_{2}\right.} \\
& \left.\quad+x S_{2}+z S_{2}-x z S_{2}\right] y \leq-y
\end{aligned}
$$


$\left[M+T x \delta+T y \delta-T x y \delta+(-1+x+y-x y) G_{1}+(-1+x)(-1+y) G_{2}-x y G_{3}+H_{1}+H_{2}-L_{1}-L_{2}\right] z \leq-z$

According to $x, y, z \in[0,1]$, the above equation is reduced correspondingly, and the conditions of equation (15) are met:

$$
\begin{aligned}
& A_{1} \text { : when } H_{1}=k_{1}+S_{1}+B_{1}+\delta F_{1}, k_{1}+c_{1}<c_{3} \text { and } c_{1}+ \\
& H_{1}+1 \leq S_{1}+B_{1}+\delta F_{1} . \\
& A_{2} \text { : when } H_{1}<k_{1}+S_{1}+B_{1}+\delta F_{1}, c_{1}+H_{1}<S_{1}+B_{1}+ \\
& c_{3}+\delta F_{1} \text { and } c_{1}+H_{1}+1 \leq S_{1}+B_{1}+\delta F_{1} .
\end{aligned}
$$

The conditions of equation (16) are met:

$$
\begin{aligned}
& B_{1} \text { : when } H_{2}=k_{2}+S_{2}+B_{2}+\delta F_{2}, k_{2}+c_{2}<c_{3} \text { and } c_{2}+ \\
& H_{2}+1 \leq B_{2}+\delta F_{2}+S_{2} . \\
& B_{2}: \text { when } H_{2}<k_{2}+S_{2}+B_{2}+\delta F_{2}, c_{2}+H_{2}<B_{2}+\delta F_{2}+ \\
& S_{2}+c_{3} \text { and } c_{2}+H_{2}+1 \leq B_{2}+\delta F_{2}+S_{2} .
\end{aligned}
$$

The conditions of equation (17) are met:

$$
\begin{aligned}
& C_{1} \text { : when } G_{2}<T \delta+G_{1}+G_{3}, G_{2}<T \delta+G_{1} \text { and } G_{2}+ \\
& M+H_{1}+H_{2}+1 \leq G_{3}+G_{1}+L_{1}+L_{2} . \\
& C_{2} \text { : when } G_{2}<T \delta+G_{1}+G_{3}, G_{2} \leq T \delta+G_{1} \text { and } T \delta+ \\
& M+H_{1}+H_{2}+1 \leq G_{3}+L_{1}+L_{2} . \\
& C_{3} \text { : when } T \delta+G_{1}+G_{3}<G_{2}, T \delta+G_{1}<G_{2} \text { and } T \delta+M+ \\
& H_{1}+H_{2}+1 \leq G_{3}+L_{1}+L_{2} . \\
& C_{4} \text { : when } G_{2}<T \delta+G_{1}+G_{3}, T \delta+M+H_{1}+H_{2}+1 \leq \\
& G_{3}+L_{1}+L_{2} \text {. }
\end{aligned}
$$

If condition (18) is met, then it could be inferred that the trivial solution of equations (15)-(17) are moment exponentially stable. That is to say, all the players will take cooperation strategy (governments provide high subsidy, enterprises and research institutions take the strategy of substantial innovation) in the long term even though suffering from disturbance.

$$
\left(A_{1} \cup A_{2}\right) \cap\left(B_{1} \cup B_{2}\right) \cap\left(C_{1} \cup C_{2} \cup C_{3} \cup C_{4}\right) .
$$

According to condition, a "subsidy boundary" can be found for the high subsidies obtained by enterprises and institutions. Specifically, it is known that if the probability of the enterprises choosing strategic innovation converges steadily to zero, it needs to meet $H_{1} \leq k_{1}+S_{1}+B_{1}+\delta F_{1}$ in conditions $A_{1}$ and $A_{2}$. If the probability of the research institutions choosing strategic innovation converges to zero, it needs to meet $H_{2} \leq k_{2}+S_{2}+B_{2}+\delta F_{2}$ in conditions $B_{1}$ and $B_{2}$. Because the situation of enterprises and research institutions is similar, only enterprises are taken as examples. The high subsidies $\left(H_{1}\right)$ received by enterprises should not exceed the sum of the innovation enthusiasm damage $\left(K_{1}\right)$, the industrial value-added benefits $\left(S_{1}\right)$, the increased cost $\left(B_{1}\right)$, and the penalties $\left(\delta F_{1}\right)$. Therefore, we found that if the probability of strategic innovation of enterprises and research institutions is to converge steadily to zero, there exists a "subsidy boundary" for the high subsidies obtained by enterprises and institutions.

\section{Numerical Simulation and Discussion}

In this paper, the numerical simulations of equations (8)-(10) are carried out using Matlab (Version: R2017a). The variable assignment satisfies the restriction of equation (18), that is, value of variables satisfied the stability condition of zero solution of equations (8)-(10) moment exponentially stability. At this time, the government is willing to provide high subsidies and enterprises and research institutions tend to innovate substantively. Because it is difficult to obtain objective data, some variable data in this paper are obtained by experts grading method. The details are as follows: first, the probability $\delta$ of "grey interest alliance" being exposed by the society or investigated by the government is set to an intermediate value, that is, $\delta=0.5$; second, the value of the remaining variables through experts grading method was collected by questionnaires of experts.

In this paper, forty staff members of the science parks' administration committee in Beijing, Tianjin, Suzhou, and Guangzhou are selected, respectively (ten staff members in each science park), to estimate government variables. Forty business managers in four cities are selected to estimate the enterprise variables (ten managers in each city). Thirty experts from three universities in China who have participated in subsidy program were selected to estimate the relevant variables of academic and research institutions (ten experts per university). The range of variables is $0-15$, and the 2018 policy environment was took as a sample. In order to avoid the influence of abnormal values at both ends on the data, this paper selects the median score of each variable to assign the value. The data of variables are shown in Table 2.

This paper holds that the data are representative for the following reasons. First, this group of data satisfies condition (18). According to simulation results, the probability of subject strategy adoption converges to zero, so this group of data also verifies the effectiveness of condition (18). Second, the variable assignment was estimated by experts based on typical case. In summary, this paper holds that the simulation research based on the data in Table 2 is representative.

In order to observe the influence of stochastic interference more clearly, we set the random disturbance term $\sigma=2$ and simulation step length $h=0.01$. The simulation is carried out from three dimensions, the $X$ axis represents the discussion variable, the $Y$ axis indicates the evolution time $(\mathrm{N})$, and the $Z$ axis indicates the proportion $(x)$ of enterprises adopting strategic innovation, the proportion $(y)$ of academic and research institutions adopting strategic innovation, or the proportion $(z)$ of local governments giving low subsidy. When studying the time evolution of one subject's strategy adoption, we set the proportion of other two subjects' strategy adoption (enterprises and academic research institutions adopt strategic innovation strategies; local governments adopt low subsidy strategies) as 0.05 . 
TABLE 2: Data of variables.

\begin{tabular}{lc}
\hline Variable & Value \\
\hline$H_{1}$ & 5 \\
$H_{2}$ & 3 \\
$L_{1}$ & 2 \\
$L_{2}$ & 1 \\
$S_{1}$ & 14 \\
$S_{2}$ & 7 \\
$C_{1}$ & 6 \\
$C_{2}$ & 4 \\
$C_{3}$ & 1 \\
$G_{1}$ & 12 \\
$G_{2}$ & 4 \\
$G_{3}$ & 2 \\
$G_{4}$ & 3 \\
$K_{1}$ & 3 \\
$K_{2}$ & 2 \\
$B_{1}$ & 2 \\
$B_{2}$ & 2 \\
$M$ & 1 \\
$\delta$ & 1 \\
$T$ & 0.5 \\
$F_{1}$ & 3 \\
$F_{2}$ & 3 \\
\hline
\end{tabular}

5.1. Variables' Directional Impact on the Strategy Adoption of Different Subjects. With the change of variables' value, the influence on the strategy adoption has significant directional difference, which can be divided into three situations.

The first is the "stable type." As shown in Figures 2 and 3 , when the value of substantial innovation investment $\left(C_{3}\right)$ and social income $\left(G_{3}\right)$ increases, the proportion $(x)$ of enterprises choosing strategic innovation and the proportion $(z)$ of local governments choosing to give low subsidies will tend to be stable. In particular, as shown in Figure 2, when $N=38$, the variation range of the proportion of subject's strategy adoption is less than $2.7 \%$. That is to say, the change of variables has little influence on subject's strategy adoption in random interference environment.

The second is the "weakening type." As shown in Figure 4 , the proportion $(x)$ of enterprises choosing strategic innovation decreases dramatically with the increasing punishment $\delta F_{1}$. Especially, when $N=38$, the proportion $(x)$ dropped from $16.5 \%$ to $0.6 \%$. The variation range of the proportion $(x)$ is more than $15.9 \%$. Compared with the effects of other variables, raising the penalty of the "grey interest alliance" after investigation can significantly promote substantive innovation of enterprises.

The third is the "enhanced type." As shown in Figures 5-7, when the high subsidies $H_{1}$, the cost input $C_{1}$, and the reputation cost $\delta T$ increase, the proportion $(x)$ of enterprises choosing strategic innovation and the proportion $(z)$ of local governments choosing to give low subsidy will continue to increase. In addition, the proportion $(x)$ of enterprises will be significantly increased with the increase of high subsidy $\left(H_{1}\right)$. As shown in Figure 5 , when $N=38$, the proportion $(x)$ of enterprises choosing strategic innovation increased from $3.2 \%$ to
$77.2 \%$, and the variation range of the proportion $(x)$ is $74 \%$. Therefore, under the random interference environment, blindly increasing subsidy to enterprises will encourage the motivation of enterprises' strategic innovation, which is not conducive to enterprises' innovation. Similarly, when the cost of substantial innovation of enterprises increases, enterprises are also more inclined to strategic innovation. Therefore, the government should give priority to helping enterprises reduce costs instead of increasing subsidy.

5.2. Variables Have Degree Impact on the Strategy Adoption of Different Subjects. The first type is "overall severe fluctuation." As shown in Figures 3 and 7, the proportion $(z)$ of local governments choosing to give low subsidy will fluctuate dramatically as time goes by. That is to say, the local governments have a high "sensitivity" to social benefit $\left(G_{3}\right)$ and reputation damage $(\delta T)$. This is in line with the reality of China. When R\&D deception is exposed, the local governments tend to cover up the facts to avoid further deterioration. But when public opinion continues to ferment or higher authorities intervene, local governments often cannot control the spread of scandal. Therefore, once the Chinese $\mathrm{R} \& \mathrm{D}$ deception is exposed, it is often a big case. Local governments also have moral hazard when they supervise the "grey interest alliance." Although "grey interest alliance" cannot promote substantive innovation, it can bring the local "reputation" benefits, such as the establishment of important R\&D programs. On the other hand, local governments need to invest supervision costs. Therefore, the social benefits of "grey interest alliance" will push the local governments to "swing" between providing high and low subsidy, as shown in Figure 3.

The second type is two-end fluctuation heterogeneity. As shown in Figure 4, when the value of regulatory punishment $\left(\delta F_{1}\right)$ is low, the proportion $(x)$ of enterprises choosing strategic innovation fluctuates violently. When the value of regulatory punishment $\left(\delta F_{1}\right)$ increases, the fluctuation of proportion $(x)$ will become gentle. When the value of regulatory punishment $\left(\delta F_{1}\right)$ is low, the enterprises' behavior of strategy adoption is highly speculative. Enterprises will quickly switch between substantive innovation and strategic innovation. When the value of regulatory punishment $\left(\delta F_{1}\right)$ is high, enterprises are determined to choose substantive innovation because they cannot bear the punishment.

In addition, as shown in Figures 5 and 6, when the value of high subsidies $H_{1}$ and enterprise substantive innovation cost $\left(C_{1}\right)$ is low, the proportion $(x)$ of enterprises choosing strategic innovation stability converges to zero. But when the subsidies $H_{1}$ and enterprise substantive innovation cost $\left(C_{1}\right)$ are at a high value, the proportion $(x)$ of enterprise's strategy adoption fluctuates violently. Especially when the subsidy is at a high value, the fluctuation is very significant. It shows that the motivation of enterprises to choose strategic innovation is greatly enhanced at this time, and enterprises tend to speculate. Therefore, we found that innovation subsidy is not as high as possible. On the contrary, excessive 


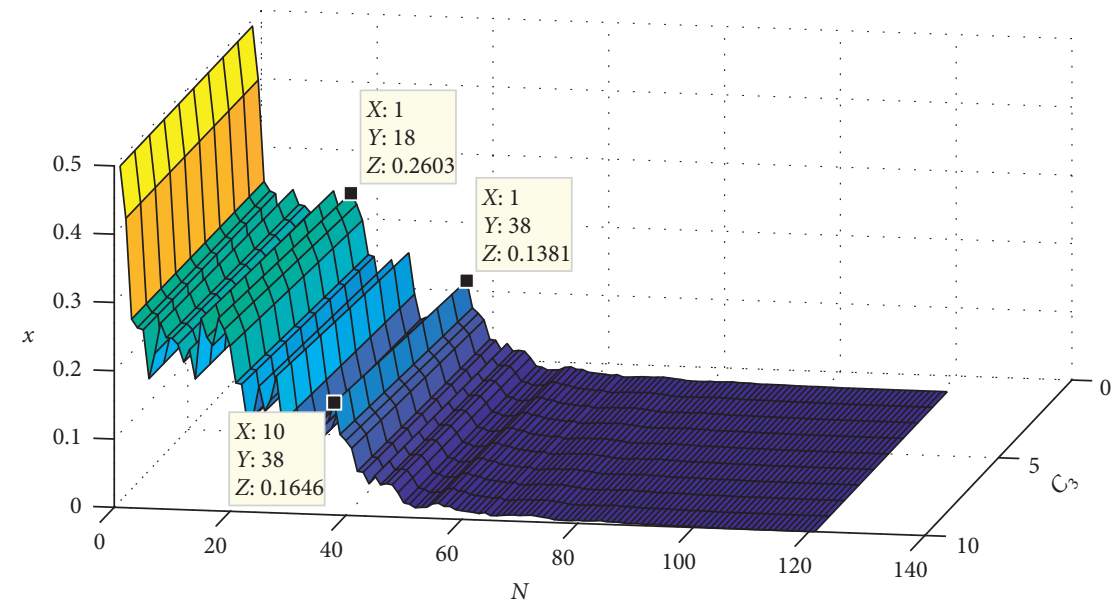

Figure 2: The impact of substantive innovation cost $\left(C_{3}\right)$ on enterprises' innovation strategy adoption.

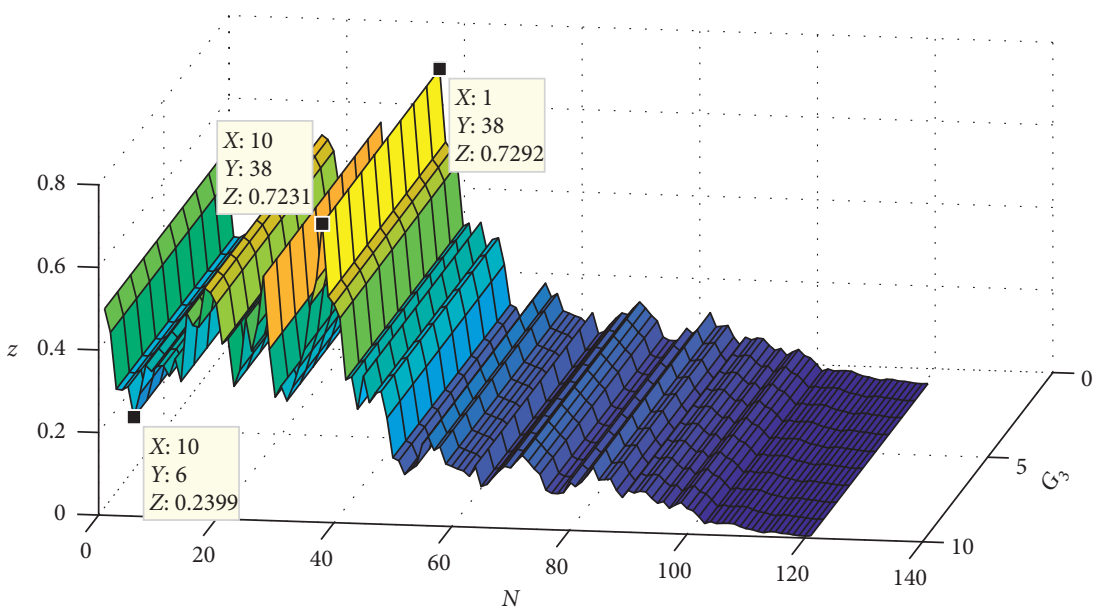

FIGURE 3: The impact of social benefit $\left(G_{3}\right)$ on the local governments' innovation strategy adoption.

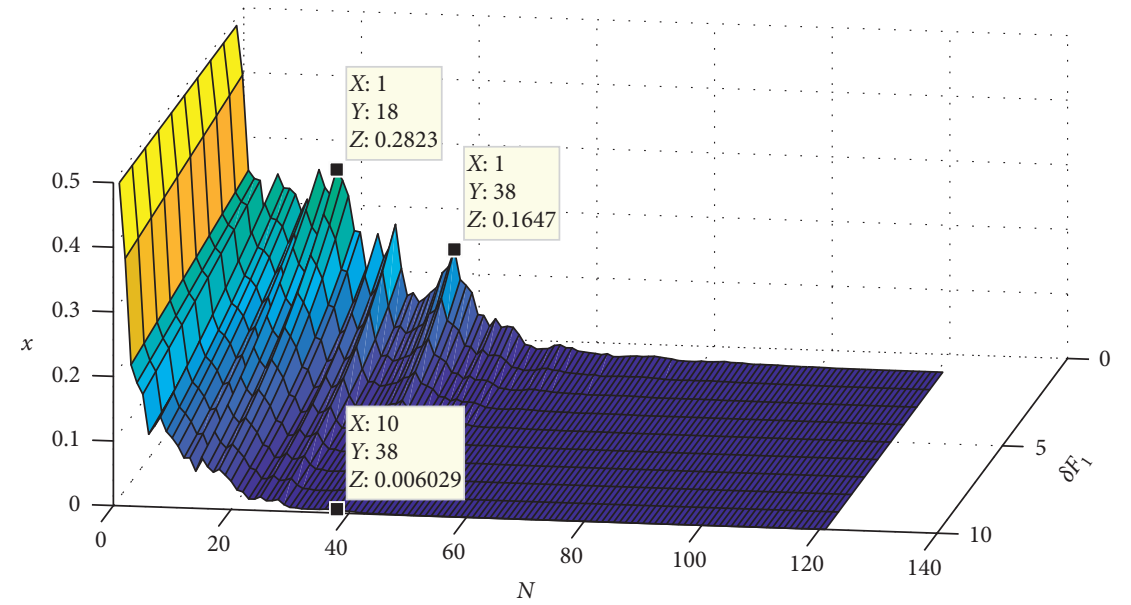

Figure 4: The impact of the regulatory punishment $\left(\delta F_{1}\right)$ on enterprises' innovation strategy adoption.

innovation subsidy is not conducive to substantive innovation and the same as substantive innovation investment of enterprises. Excessive investment in innovation will greatly dampen the enthusiasm of enterprises innovation, and it will make it easier for enterprises to generate speculative psychology. 


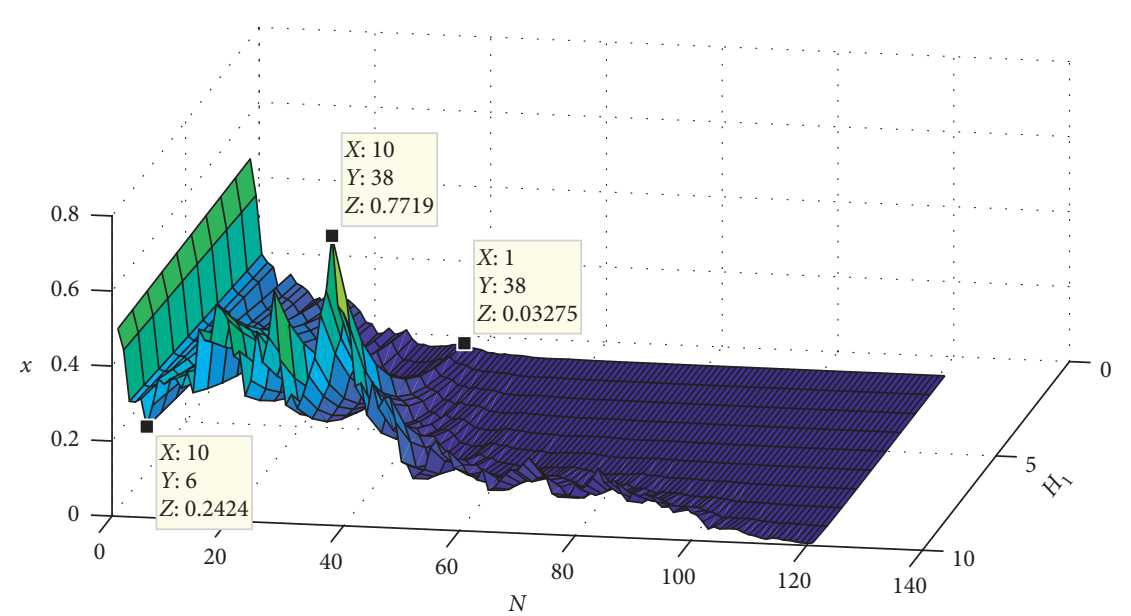

Figure 5: The impact of high subsidy $\left(H_{1}\right)$ on enterprises' innovation strategy adoption.

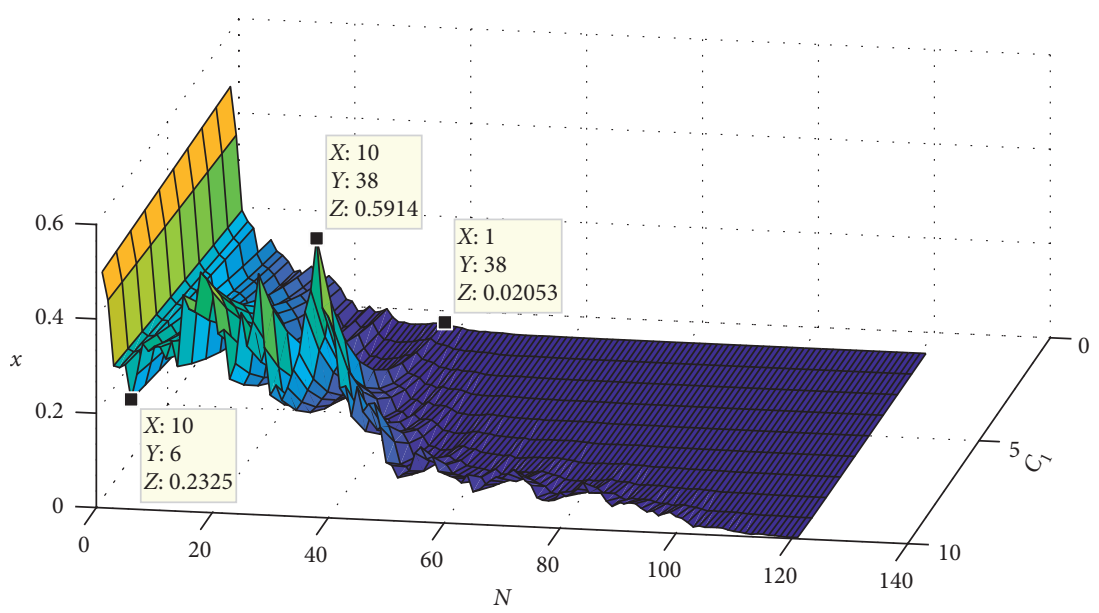

Figure 6: The impact of enterprise substantive innovation cost $\left(C_{1}\right)$ on the enterprises' innovation strategy adoption.

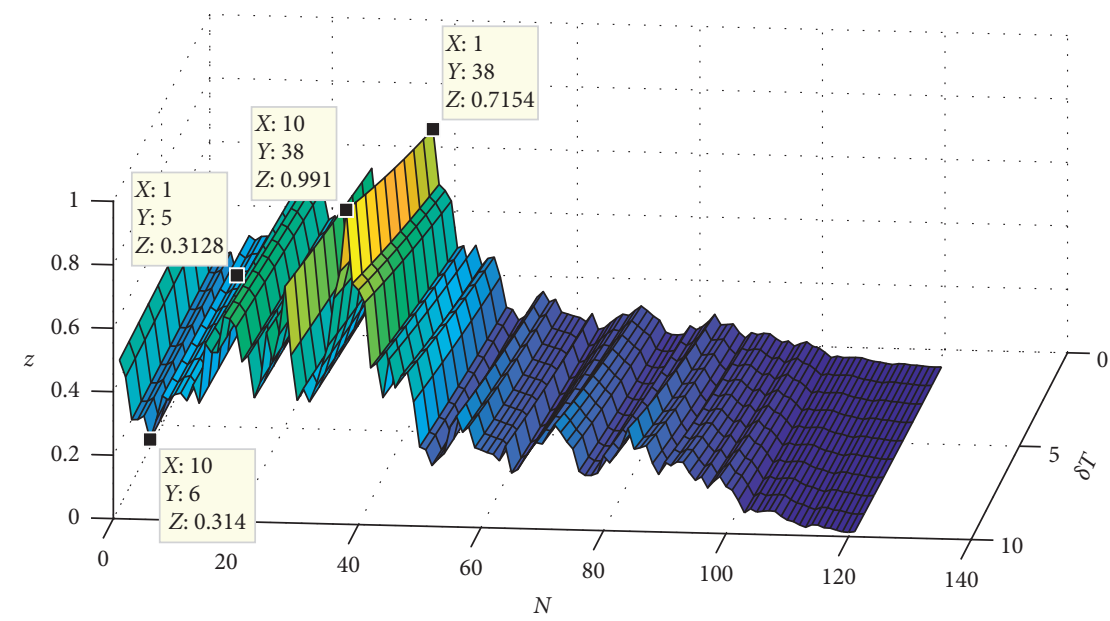

FIGURE 7: The impact of reputation damage $(\delta T)$ on the local governments' innovation strategy adoption. 
The third type is overall flat fluctuation. As shown in Figure 2, in the random environment, the substantial innovation cost $C_{3}$ of enterprises has no significant impact on enterprise's innovation strategy adoption. It shows that in the case of "grey interest alliance," the "sensitivity" of enterprises' innovation strategy adoption lies in whether there will be substantial innovation investment, not in the amount of substantive innovation investment. In addition, comparing Figure 2 with Figure 6, we found an interesting result. On the one hand, when the "grey interest alliance" is not formed, enterprises tend to choose strategic innovation with the increase of substantive innovation investment. On the other hand, when the "grey interest alliance" is formed, the proportion $(x)$ of enterprises choosing strategic innovation converges to zero steadily.

\section{Conclusion and Suggestion}

In the past few years, it has become an important and urgent topic to promote the substantive innovation of enterprises and academic research institutions in China. We developed a multiagent stochastic evolutionary game model, including enterprises, academic and research institutions, and local governments and found the boundary condition of high subsidies. Based on this, we also collected the data of variables by questionnaire survey. Through the simulation, the variables that affect the subject's strategy adoption in random environment are analyzed. We got some important conclusions as follows.

First, local governments can promote substantial innovation of enterprises and research institutions by providing high subsidies, but the subsidies should have boundaries. That is to say, the high subsidies $\left(H_{1}\right)$ received by enterprises should not exceed the sum of the innovation enthusiasm damage $\left(K_{1}\right)$, the industrial value-added benefits $\left(S_{1}\right)$, the increased cost $\left(B_{1}\right)$, and the penalties $\left(\delta F_{1}\right)$.

Second, variables have directional impact on strategy adoption of different subjects under the environment of random interference. When the value of substantial innovation investment $\left(C_{3}\right)$ of enterprises and social income $\left(G_{3}\right)$ increase continuously, the impact on the subject's innovation adoption is very weak. This kind of effect presents stable state. On the other hand, when the regulatory punishment $\left(\delta F_{1}\right)$ increases continuously, the proportion of enterprises adopting strategic innovation strategy will decrease rapidly. This kind of effect presents weak state. When the high subsidies $\left(H_{1}\right)$, the enterprise substantive innovation cost $\left(C_{1}\right)$, and reputation damage $(\delta T)$ increase continuously, the proportion of enterprises adopting strategic innovation and local governments choosing to give low subsidy continues to increase, showing an "enhanced" state.

Third, variables have degree impact on strategy adoption of different subjects. The impact of reputation damage $(\delta T)$ and social benefit $\left(G_{3}\right)$ on the choice of local governments strategy shows the characteristics of "overall severe fluctuation," that is to say, regardless of whether the value of variable is low or high, the proportion of local government strategy adoption fluctuates violently. The impact of regulatory punishment $\left(\delta F_{1}\right)$, high subsidy $\left(H_{1}\right)$, and enterprise substantive innovation cost $\left(C_{1}\right)$ on the proportion of subject strategy adoption shows the characteristics of "twoend fluctuation heterogeneity." Specifically, when the value of regulatory punishment $\left(\delta F_{1}\right)$ is small, the proportion of the enterprises choosing strategic innovation fluctuates violently. The decision of enterprises under the random environment is highly uncertain. And enterprises will make rapid changes between strategic and substantive innovation strategies. In addition, when the value of high subsidy $\left(H_{1}\right)$ and enterprise substantive innovation cost $\left(C_{1}\right)$ is low, the fluctuation of proportion is very weak. On the contrary, when the value of high subsidy $\left(H_{1}\right)$ and enterprise substantive innovation cost $\left(C_{1}\right)$ is high, the fluctuation of proportion is very violent. When the grey interest alliance is formed, the impact of social benefit $\left(G_{3}\right)$ on enterprise's strategy adoption shows the characteristic of "overall flat fluctuation." That is, regardless of whether the variable value is high or low, the impact on the subject strategy adoption is not significant.

In order to achieve the goal of promoting innovation and development and encourage local governments to support substantive innovation of enterprises and academic institutions by high subsidy, we put forward the following policy implications.

First, local governments should give full consideration to the amount of subsidies. On the one side, when the government's innovation subsidy exceeds a certain amount, the innovation willingness of enterprises and research institutions will not be affected by the innovation subsidy. Besides, the excessive innovation subsidy is not conducive to substantive innovation of enterprises and academic institutions. On the other hand, innovation subsidy should also have a boundary. The high subsidies received by enterprises should not exceed the sum of the innovation enthusiasm damage, the industrial value-added benefits, the increased cost, and the penalties.

Second, from the perspective of regulatory efficiency of the superior competent department, reducing the high subsidies received by enterprises and substantial innovation cost of enterprises can promote enterprises to take the strategy of substantial innovations. But the impact of reducing the high subsidy on the promotion of the substantive innovation of the enterprises is more significant. Therefore, reduction of subsidies should be considered first when government funds are limited. In addition, compared with the benefit from the "grey interest alliance," local governments pay more attention to reputation damage. Therefore, it is necessary to change the performance appraisal system of local governments, which only focus on the quantity of innovation (such as quantity of patents and R\&D projects). Damage to innovation reputation should also be included in the performance appraisal system.

Third, we must not rely too much on high subsidies to promote innovation cooperation. We should moderately turn the direct subsidy of innovation into support of subject's innovation cost. This will greatly reduce the proportion of strategic innovation behavior of enterprises and research institutions under the highly uncertain innovation environment. In addition to supporting the 
"innovation hardware" of enterprises, innovation subsidies should also pay attention to the "innovation environment" of enterprises.

\section{Data Availability}

The data used to support the findings of this study are included within the article.

\section{Conflicts of Interest}

The authors declare that there are no conflicts of interest regarding the publication of this paper.

\section{Acknowledgments}

This study was supported by the National Natural Science Foundation of China (no. 71272048).

\section{References}

[1] E. Özçelik and E. Taymaz, "R\&D support programs in developing countries: the Turkish experience," Research Policy, vol. 37, no. 2, pp. 258-275, 2008.

[2] B. Aschhoff, The Effect of Subsidies on R\&D Investment and Success-Do Subsidy History and Size Matter?, Zentrum für Europäische Wirtschaftsforschung, Mannheim, Germany, 2009.

[3] O. Gassmann, E. Enkel, and H. Chesbrough, "The future of open innovation," R\&D Management, vol. 40, no. 3, pp. 213-221, 2010.

[4] V. A. Aggarwal, N. Siggelkow, and H. Singh, "Governing collaborative activity: interdependence and the impact of coordination and exploration," Strategic Management Journal, vol. 32, no. 7, pp. 705-730, 2011.

[5] S. Heil and T. Bornemann, "Creating shareholder value via collaborative innovation: the role of industry and resource alignment in knowledge exploration," R\&D Management, vol. 48, no. 4, pp. 394-409, 2017.

[6] K.-H. Tsai, "Collaborative networks and product innovation performance: toward a contingency perspective," Research Policy, vol. 38, no. 5, pp. 765-778, 2009.

[7] M. J. Nieto and L. Santamaría, "The importance of diverse collaborative networks for the novelty of product innovation," Technovation, vol. 27, no. 6-7, pp. 367-377, 2007.

[8] C. Lindsay, P. Findlay, J. McQuarrie, M. Bennie, E. D. Corcoran, and R. Van Der Meer, "Collaborative innovation, new technologies, and work redesign," Public Administration Review, vol. 78, no. 2, pp. 251-260, 2017.

[9] Z. Wang, "Knowledge integration in collaborative innovation and a self-organizing model," International Journal of Information Technology \& Decision Making, vol. 11, no. 2, pp. 427-440, 2012.

[10] L. Dooley, B. Kenny, and M. Cronin, "Interorganizational innovation across geographic and cognitive boundaries: does firm size matter?" R\&D Management, vol. 46, no. S1, pp. 227-243, 2016.

[11] E. Albats, I. Fiegenbaum, and J. A. Cunningham, “A micro level study of university industry collaborative lifecycle key performance indicators," The Journal of Technology Transfer, vol. 43, no. 2, pp. 389-431, 2018.

[12] A. Schulze and G. J. C. Brojerdi, "The effect of the distance between partners' knowledge components on collaborative innovation," European Management Review, vol. 9, no. 2, pp. 85-98, 2012.

[13] J. Zhao, G. Wu, X. Xi, Q. Na, and W. Liu, "How collaborative innovation system in a knowledge-intensive competitive alliance evolves? An empirical study on China, Korea and Germany," Technological Forecasting and Social Change, vol. 137, pp. 128-146, 2018.

[14] Z. Yang, V. T. Nguyen, and P. B. Le, "Knowledge sharing serves as a mediator between collaborative culture and innovation capability: an empirical research," Journal of Business \& Industrial Marketing, vol. 33, no. 7, pp. 958-969, 2018.

[15] I. De Noni, L. Orsi, and F. Belussi, "The role of collaborative networks in supporting the innovation performances of lagging-behind European regions," Research Policy, vol. 47, no. 1, pp. 1-13, 2018.

[16] J. Guan and N. Liu, "Exploitative and exploratory innovations in knowledge network and collaboration network: a patent analysis in the technological field of nano-energy," Research Policy, vol. 45, no. 1, pp. 97-112, 2016.

[17] S. Najafi-Tavani, Z. Najafi-Tavani, P. Naudé, P. Oghazi, and E. Zeynaloo, "How collaborative innovation networks affect new product performance: product innovation capability, process innovation capability, and absorptive capacity," Industrial Marketing Management, vol. 73, pp. 193-205, 2018.

[18] X. Xie, L. Fang, and S. Zeng, "Collaborative innovation network and knowledge transfer performance: a fsQCA approach," Journal of Business Research, vol. 69, no. 11, pp. 5210-5215, 2016.

[19] R. Crescenzi, M. Nathan, and A. Rodríguez-Pose, "Do inventors talk to strangers? on proximity and collaborative knowledge creation," Research Policy, vol. 45, no. 1, pp. 177-194, 2016.

[20] G. Cerulli and B. Potì, "The differential impact of privately and publicly funded R\&D on R\&D investment and innovation: the Italian case," Prometheus, vol. 30, no. 1, pp. 113-149, 2012.

[21] C. Wang, P.-y. Nie, D.-h. Peng, and Z.-h. Li, "Green insurance subsidy for promoting clean production innovation," Journal of Cleaner Production, vol. 148, pp. 111-117, 2017.

[22] M. Greco, M. Grimaldi, and L. Cricelli, "Hitting the nail on the head: exploring the relationship between public subsidies and open innovation efficiency," Technological Forecasting and Social Change, vol. 118, pp. 213-225, 2017.

[23] X. Chang, J. Wu, T. Li, and T.-J. Fan, “The joint tax-subsidy mechanism incorporating extended producer responsibility in a manufacturing-recycling system," Journal of Cleaner Production, vol. 210, pp. 821-836, 2019.

[24] K.-H. Tsai and Y.-C. Liao, "Sustainability strategy and ecoinnovation: a moderation model," Business Strategy and the Environment, vol. 26, no. 4, pp. 426-437, 2017.

[25] Q. Huang, M. S. Jiang, and J. Miao, "Effect of government subsidization on Chinese industrial firms' technological innovation efficiency: a stochastic frontier analysis," Journal of Business Economics and Management, vol. 17, no. 2, pp. 187-200, 2016.

[26] G. Chapman, A. Lucena, and S. Afcha, "R\&D subsidies \& external collaborative breadth: differential gains and the role of collaboration experience," Research Policy, vol. 47, no. 3, pp. 623-636, 2018.

[27] A. Catozzella and M. Vivarelli, "The possible adverse impact of innovation subsidies: some evidence from Italy," International Entrepreneurship and Management Journal, vol. 12, no. 2, pp. 351-368, 2016. 
[28] A. Wu, "The signal effect of government R\&D subsidies in China: does ownership matter?” Technological Forecasting and Social Change, vol. 117, pp. 339-345, 2017.

[29] J. Wei and Y. Zuo, "The certification effect of R\&D subsidies from the central and local governments: evidence from China," R\&D Management, vol. 48, no. 5, pp. 615-626, 2018.

[30] T. Morimoto, "Occupational choice and entrepreneurship: effects of R\&D subsidies on economic growth," Journal of Economics, vol. 123, no. 2, pp. 161-185, 2018.

[31] X. Sun, X. Liu, Y. Wang, and F. Yuan, "The effects of public subsidies on emerging industry: an agent-based model of the electric vehicle industry," Technological Forecasting and Social Change, vol. 140, pp. 281-295, 2019.

[32] J. Chen, C. S. Heng, B. C. Y. Tan, and Z. Lin, "The distinct signaling effects of $R \& D$ subsidy and non-R\&D subsidy on IPO performance of IT entrepreneurial firms in China," Research Policy, vol. 47, no. 1, pp. 108-120, 2018.

[33] D. Dai and K. Shen, "IPR protection vs. innovation subsidy: what is the choice for the emerging south?" The Journal of International Trade \& Economic Development, vol. 25, no. 3, pp. 426-451, 2016.

[34] P. Boeing, "The allocation and effectiveness of China's R\&D subsidies-evidence from listed firms," Research Policy, vol. 45, no. 9, pp. 1774-1789, 2016.

[35] R. Bronzini and P. Piselli, "The impact of R\&D subsidies on firm innovation," Research Policy, vol. 45, no. 2, pp. 442-457, 2016.

[36] L. Cheng, H. Cheng, and Z. Zhuang, "Political connections, corporate innovation and entrepreneurship: evidence from the China employer-employee survey (CEES)," China Economic Review, vol. 54, pp. 286-305, 2019.

[37] S. A. Basit, T. Kuhn, and M. Ahmed, "The effect of government subsidy on non-technological innovation and firm performance in the service sector: evidence from Germany," Business Systems Research Journal, vol. 9, no. 1, pp. 118-137, 2018.

[38] W. Zuo, Y. Li, and Y. Wang, "Research on the optimization of new energy vehicle industry research and development subsidy about generic technology based on the three-way decisions," Journal of Cleaner Production, vol. 212, pp. 46-55, 2019.

[39] X. Deng, D. Han, J. Dezert, Y. Deng, and Y. Shyr, "Evidence combination from an evolutionary game theory perspective," IEEE Transactions on Cybernetics, vol. 46, no. 9, pp. 20702082, 2016.

[40] H. Xu, C. Tian, S. Fan, and J. Li, "Information flows in the market: an evolutionary game approach," Chaos: An Interdisciplinary Journal of Nonlinear Science, vol. 29, no. 2, Article ID 023126, 2019.

[41] M. K. Jensen and A. Rigos, "Evolutionary games and matching rules," International Journal of Game Theory, vol. 47, no. 3, pp. 707-735, 2018.

[42] X. Liu, M. Hu, X. Yu, X. Peng, M. Yu, and H. Gong, “Analysis of water rights trading mechanism based on evolutionary game," Desalination and Water Treatment, vol. 121, pp. 202-207, 2018.

[43] Y. e. Wu, B. Zhang, and S. Zhang, "Probabilistic reward or punishment promotes cooperation in evolutionary games," Chaos, Solitons \& Fractals, vol. 103, pp. 289-293, 2017.

[44] P. Buckley, S. Noonan, C. Geary, T. Mackessy, and E. Nagle, "An empirical study of gamification frameworks," Journal of Organizational and End User Computing, vol. 31, no. 1, pp. 22-38, 2019.
[45] A. Shahri, M. Hosseini, K. Phalp, J. Taylor, and R. Ali, "How to engineer gamification: the consensus, the best practice and the grey areas," Journal of Organizational and End User Computing, vol. 31, no. 1, pp. 39-60, 2019.

[46] H. Xie, W. Wang, and X. Zhang, "Evolutionary game and simulation of management strategies of fallow cultivated land: a case study in Hunan province, China," Land Use Policy, vol. 71, pp. 86-97, 2018.

[47] Q. Shi, J. Zhu, and Q. Li, "Cooperative evolutionary game and applications in construction supplier tendency," Complexity, vol. 2018, Article ID 8401813, 13 pages, 2018.

[48] Z. Yang, Y. Shi, and Y. Li, "Analysis of intellectual property cooperation behavior and its simulation under two types of scenarios using evolutionary game theory," Computers \& Industrial Engineering, vol. 125, pp. 739-750, 2018.

[49] A. Antoci and F. Sabatini, "Online networks, social interaction and segregation: an evolutionary approach," Journal of Evolutionary Economics, vol. 28, no. 4, pp. 859-883, 2018.

[50] S. Encarnação, F. P. Santos, F. C. Santos, V. Blass, J. M. Pacheco, and J. Portugali, "Paths to the adoption of electric vehicles: an evolutionary game theoretical approach," Transportation Research Part B: Methodological, vol. 113, pp. 24-33, 2018.

[51] T. Shu, Y. Wang, S. Chen, S. Wang, K. K. Lai, and Y. Yang, "Analysis of evolutionary game in structural formation of market power in remanufacturing supply chains," Applied Economics, vol. 51, no. 20, pp. 2195-2220, 2019.

[52] H. Cui, T. Zhao, and P. Tao, "Evolutionary game study on the development of green agriculture in China based on ambidexterity theory perspective," Polish Journal of Environmental Studies, vol. 28, no. 3, pp. 1093-1104, 2019.

[53] Q. Liu, X. Li, and X. Meng, "Effectiveness research on the multi-player evolutionary game of coal-mine safety regulation in China based on system dynamics," Safety Science, vol. 111, pp. 224-233, 2019.

[54] M. Wang, "Evolutionary game theory based evaluation system of green building scheme design," Cognitive Systems Research, vol. 52, pp. 622-628, 2018.

[55] W. Chen and Z.-H. Hu, "Using evolutionary game theory to study governments and manufacturers' behavioral strategies under various carbon taxes and subsidies," Journal of Cleaner Production, vol. 201, pp. 123-141, 2018.

[56] H. Sun, X. Wang, and Y. Xue, "Stochastic evolutionary game model for unexpected incidents involving mass participation based on different scenarios," Operations Research Management Science, vol. 25, pp. 23-30, 2016, in Chinese.

[57] C. T. H. Baker and E. Buckwar, "Exponential stability in $p$-th mean of solutions, and of convergent Euler-type solutions, of stochastic delay differential equations," Journal of Computational and Applied Mathematics, vol. 184, no. 2, pp. 404427, 2005.

[58] Y. Xu, B. Yu, Y. Wang, and Y. Chen, "A stochastic evolutionary game perspective on the stability of strategic alliances against external opportunism," Journal of Systems Science and Complexity, vol. 28, no. 4, pp. 978-996, 2015. 